\title{
Mesoscale eddies northeast of the Hawaiian archipelago from satellite altimeter observations
}

\author{
Shuiming Chen ${ }^{1}$ and Bo Qiu ${ }^{1}$ \\ Received 7 August 2009; revised 1 October 2009; accepted 7 October 2009; published 16 March 2010.
}

[1] Enhanced mesoscale eddy activity northeast of the Hawaiian archipelago was investigated by using the high-pass filtered satellite altimetric sea surface height (SSH) data of the past 16 years. The level of eddy kinetic energy (EKE) shows significant interannual variations, which appear well correlated to the large-scale atmospheric wind forcing associated with the Pacific Decadal Oscillation index; the EKE levels in the area along the Subtropical Front zone in 1997-1998 and 2003-2005, for example, were three times as large as those in the low EKE years. Spectral analyses in the $3^{\circ}$ latitude by $5^{\circ}$ longitude subregions revealed the dominant mesoscale periods ranging from 90 days near $18^{\circ} \mathrm{N}$ to 180 days near $36^{\circ} \mathrm{N}$. A $3 \frac{1}{2}$-layer quasi-geostrophic model constrained by World Ocean Atlas 2005 climatologies was used to explore instability of the regional circulation. The analysis shows a geographical match between baroclinic instability strength and the observed RMS SSH variability and a temporal match between seasonally varying instability strength and the observed seasonal EKE modulation, and suggests that baroclinic instability by the vertically sheared, regional mean circulation provides the energy source for the enhanced eddy variability northeast of the Hawaiian archipelago.

Citation: Chen, S., and B. Qiu (2010), Mesoscale eddies northeast of the Hawaiian archipelago from satellite altimeter observations, J. Geophys. Res., 115, C03016, doi:10.1029/2009JC005698.

\section{Introduction}

[2] With high-precision sea surface height (SSH) information being continuously acquired by satellite altimeters for more than 15 years, ocean surface mesoscale eddy variability is now well mapped. In the open ocean of the North Pacific between $10^{\circ} \mathrm{N}$ and $45^{\circ} \mathrm{N}$, mesoscale SSH variability is dominated by two zonal bands, one along the Kuroshio Extension centered at $35^{\circ} \mathrm{N}$ and the other around $20^{\circ} \mathrm{N}-25^{\circ} \mathrm{N}$ (Figure 1). Although these two highmesoscale variability bands were identified earlier by the use of ship drifting data [Wyrtki et al., 1976] and historical hydrographic records [Wyrtki, 1975], their temporal variability and underlying dynamics have become clearer after the altimetric observations. The strong mesoscale eddy activity in the Kuroshio Extension band varies predominantly on decadal timescales, corresponding with the stable and unstable states of the Kuroshio Extension jet [Qiu and Chen, 2005]. Along the $20^{\circ} \mathrm{N}-25^{\circ} \mathrm{N}$ band west of the date line, mesoscale eddies are generated from baroclinic instability of the mean flow shear consisting of surface, eastward-flowing North Pacific Subtropical Countercurrent (NPSTCC) and subsurface, westward-flowing North Equatorial Current [Qiu, 1999]. Between the date line and the Hawaiian Islands along $\sim 20^{\circ} \mathrm{N}$, the enhanced eddy activity is related to baroclinic instability of the Hawaiian Lee

\footnotetext{
${ }^{1}$ Department of Oceanography, University of Hawai'i at Mānoa, Honolulu, Hawaii, USA.

Copyright 2010 by the American Geophysical Union. 0148-0227/10/2009JC005698
}

Countercurrent [Kobashi and Kawamura, 2002] and to the surface wind forcing in the lee of the Hawaiian Islands [Lumpkin, 1998; Calil et al., 2008].

[3] The focus of this study is the enhanced mesoscale eddy variability northeast of the Hawaiian archipelago, which extends northwestward for more than $2000 \mathrm{~km}$ from the island of Hawaii at $20^{\circ} \mathrm{N}, 156^{\circ} \mathrm{W}$ to the Midway Islands at $30^{\circ} \mathrm{N}, 180^{\circ} \mathrm{E}$ [Qiu et al., 1997] (see Figure 1). Evidence for this enhanced mesoscale eddy variability can be found in the early eddy kinetic energy (EKE) map from ship drift charts [Wyrtki et al., 1976] and the RMS SSH map from 1978 Seasat Mission [Cheney et al., 1983]. A similar picture can be seen in more recent EKE maps from the surface drifter measurements [Niiler, 2001; Lumpkin, 1998] and in RMS SSH maps from the satellite altimeter missions after Seasat [e.g., Van Woert and Price, 1993; Mitchum, 1996]. However, temporal variations of the eddy field are not clear. In this study, making use of the longevity of the satellite altimeter observations over 16 years, we will first explore the seasonal modulation and interannual changes of the eddy activity northeast of the Hawaiian archipelago.

[4] The generation mechanism of the eddy activity northeast of the Hawaiian archipelago is distinct from that of the eddy activity west of the archipelago. Eddy variability in the lee of the Hawaiian Islands is generated by the anomalous wind patterns stemming from the blockage of the northeasterly trade winds by the Hawaiian Islands, either directly through Ekman pumping or indirectly through baroclinic instability of the wind-driven mean flow, the Hawaiian Lee Countercurrent [Lumpkin, 1998; Kobashi and Kawamura, 2002; Qiu and Durland, 2002; Calil et al., 2008]. In a 


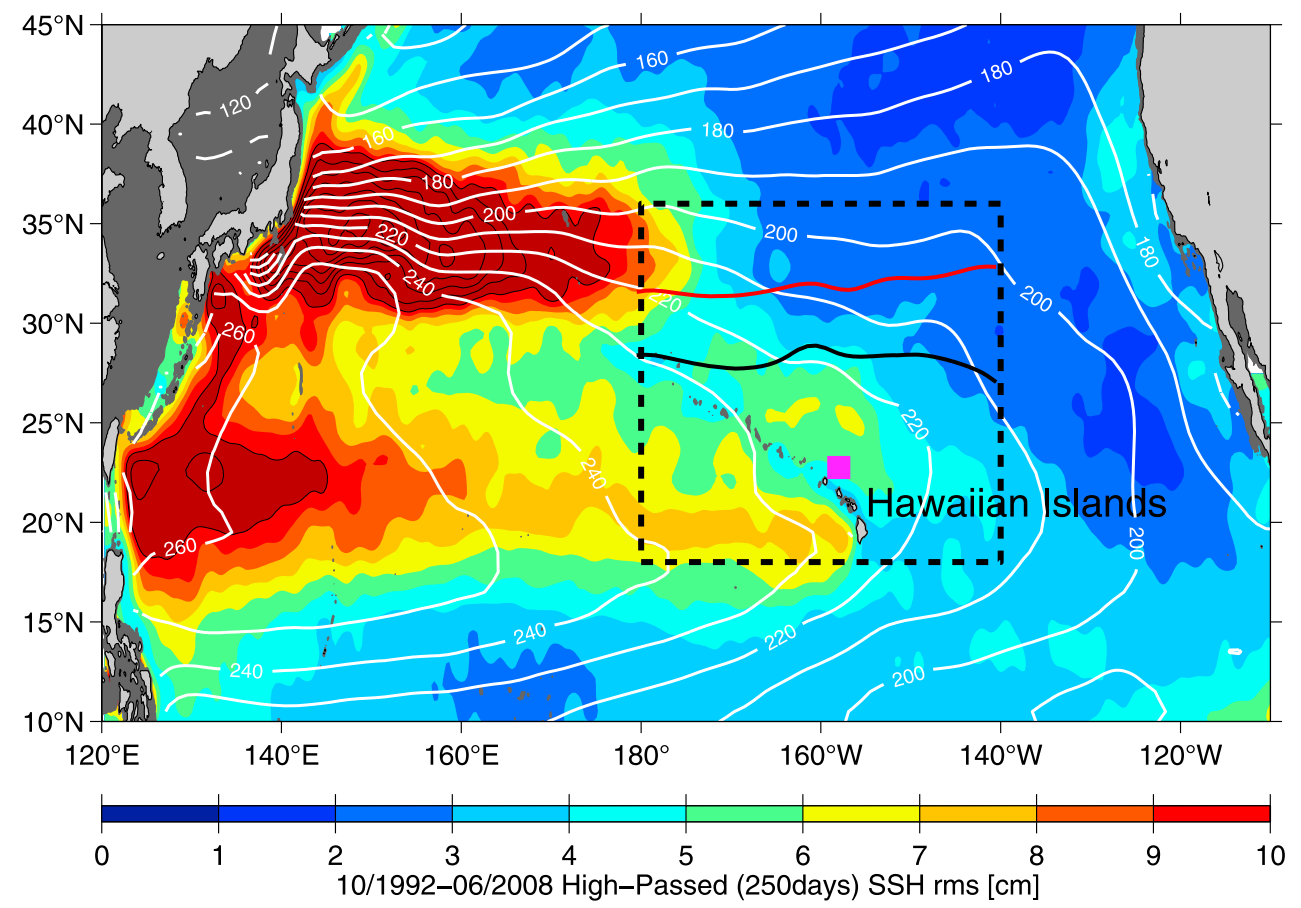

Figure 1. High-pass filtered, RMS SSH variability in North Pacific (color shading). Black Contours $(10 \mathrm{~cm}, 12 \mathrm{~cm}, \ldots)$ are added when the RMS SSH is larger than $10 \mathrm{~cm}$. The white contours are the mean surface dynamic heights in $\mathrm{cm}$ from WOA05, referenced to $1500 \mathrm{~m}$. The red and black thick lines northeast of the Hawaiian archipelago are the $17^{\circ} \mathrm{C}$ and $20^{\circ} \mathrm{C}$ isotherms of the March SST, approximating the STF zone. The dashed box indicates the study region, and the purple square denotes the ALOHA station. The area with water depth less than $500 \mathrm{~m}$ is gray shaded.

regional numerical model simulation forced by high-resolution wind products, Calil et al. [2008] were able to reproduce the EKE level leeward of the Hawaiian archipelago but not northeast of the Hawaiian archipelago, suggesting that the eddy activity on the two sides of the archipelago differs dynamically. On the basis of the TOPEX/Poseidon's first 2 year observations, Mitchum [1996] noticed that the eddy activity on the two sides of the Hawaiian archipelago was not connected. In this study, we will show that it is baroclinic instability of the mean flow associated with the subtropical gyre that provides the energy source for the elevated eddy variability northeast of the Hawaiian archipelago. Baroclinic instability was speculated by Van Woert and Price [1993] as a candidate for generation mechanism of the eddies surrounding the Hawaiian Islands. Lee and Niiler [1987] performed a baroclinic instability analysis on the mean flow in the eastern North Pacific on the basis of the pre-1975 hydrographic data and concluded that the baroclinic instability could be the energy source of observed eddy variability. To understand the latitudinal changes of the EKE level, Lee and Niiler averaged the mean flow over the regions larger than $5^{\circ}$ in latitude and $20^{\circ}$ in longitude. Here, latitudinal and longitudinal changes of the EKE level northeast of the Hawaiian archipelago, as well as its temporal variations, are studied. With much improved hydrographic climatologies, World Ocean Atlas 2005 (WOA05) [Locarnini et al., 2006; Antonov et al., 2006], our instability analysis will be performed in $3^{\circ}$ latitude by $5^{\circ}$ longitude subregions.

[5] Previous studies of the eddy activity northeast of the Hawaiian archipelago were focused on the fluctuations of the Subtropical Front (STF) zone [Roden, 1980, 1981;
Niiler and Reynolds, 1984], of which northern and southern boundaries can be approximated by the $17^{\circ} \mathrm{C}$ and $20^{\circ} \mathrm{C}$ isotherms (see the red and black contours in Figure 1). On the basis of statistics from the surface drifters, Niiler and Reynolds [1984] found a three-fold increase in EKE from $40^{\circ} \mathrm{N}$ to $20^{\circ} \mathrm{N}$ across the STF zone. This is consistent with Figure 1 in that the eddy activity is stronger south of the STF zone than north of it. In this study, by making use of high spatial and temporal resolutions of the altimetric observations, we will show that the eddy activities along the STF zone and south of the STF zone not only differ in strength but also in temporal content. EKE along the STF zone is dominated by interannual variation while that south of the STF zone shows both interannual and seasonal variations.

[6] We will first describe the mesoscale eddy variability northeast of the Hawaiian archipelago by using the altimetric SSH data (section 2). In section 3, we will perform a baroclinic instability analysis by using the $3 \frac{1}{2}$-layer quasigeostrophic $(\mathrm{QG})$ model and investigate the roles played by the mean flow, stratification, and Coriolis parameter in the instability process. Section 4 speculates a cause-effect relationship from the Pacific Decadal Oscillation (PDO) index [Mantua et al., 1997] to the EKE interannual variability. Section 5 provides a summary.

\section{Altimetric Observations}

[7] Our principle data set is the Archiving, Validation, and Interpretation of Satellite Oceanographic (AVISO) SSH anomaly data set which merges all available satellite altim- 
(a) SSH rms Northeast of Hawaiian Islands

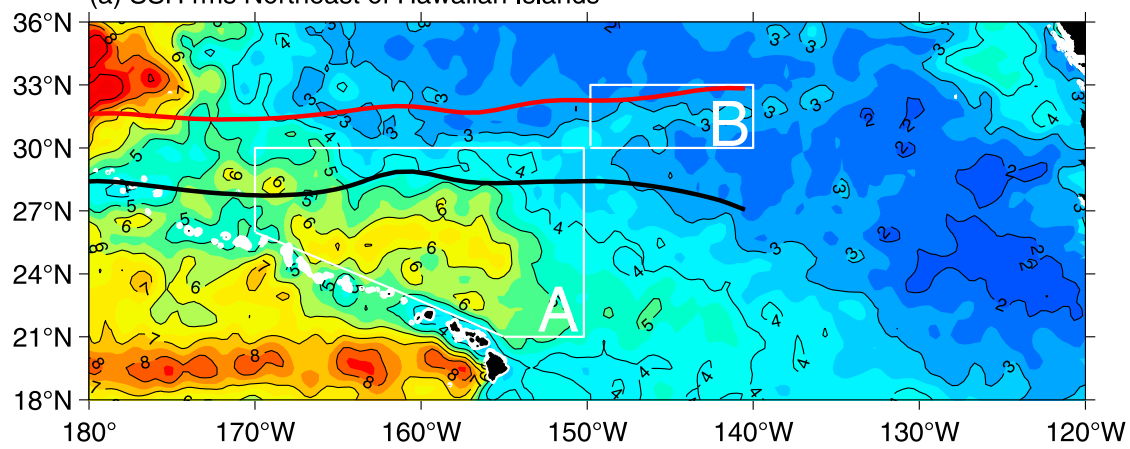

(b) SSH rms during 1997-1998 and 2003-2005

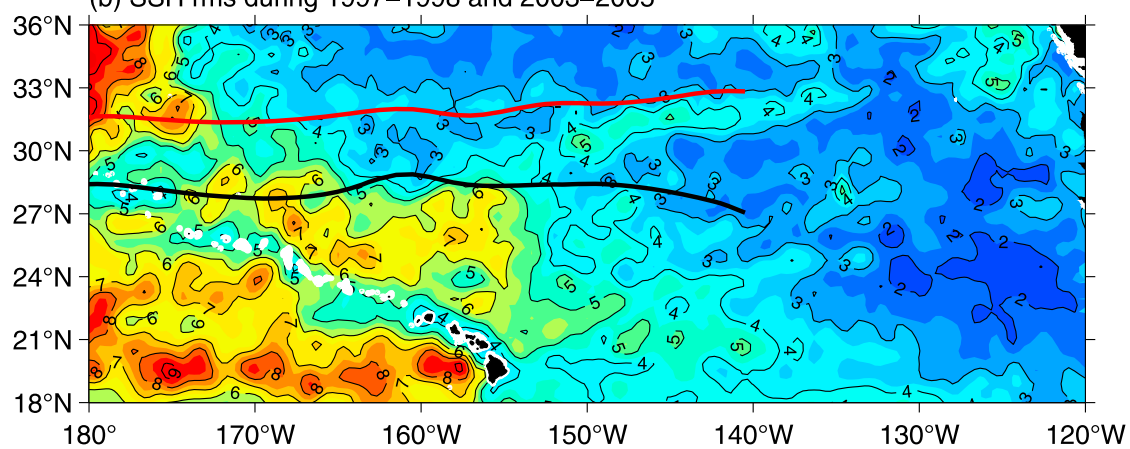

(c) SSH rms during 1993-1996, 1999-2002, and 2006-2007

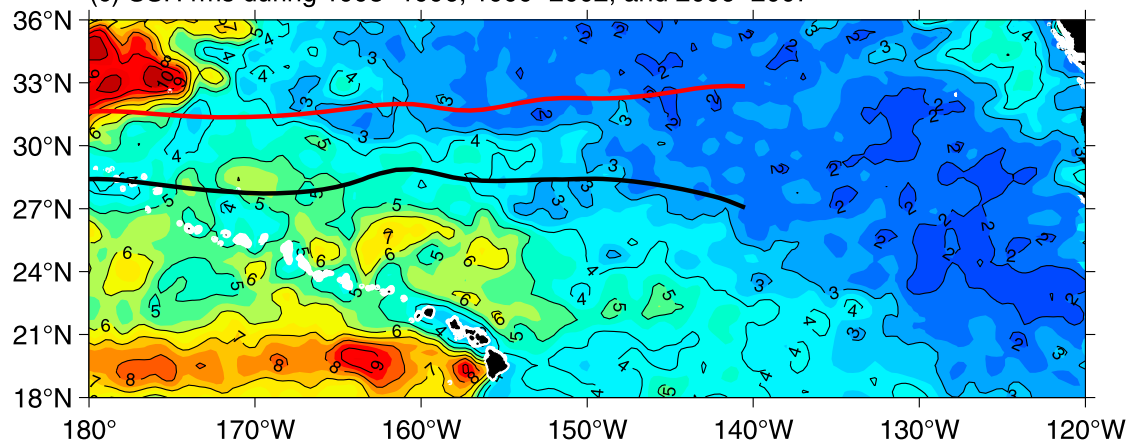

Figure 2. (a) High-pass filtered RMS SSH amplitude in $\mathrm{cm}$ around the Hawaiian archipelago; Figure 1 is the corresponding basin map. The $17^{\circ} \mathrm{C}$ (thick red) and $20^{\circ} \mathrm{C}$ (thick black) isotherms of the March SST approximate the STF zone. The EKE time series in boxes " $A$ " and "B" are shown in Figure 3 . The Hawaiian Islands and a small portion of North America are shown in black and the area with water depth less than $500 \mathrm{~m}$ is white shaded. The RMS SSH amplitude based on the segments of the high-pass filtered SSH time series (b) during 1997-1998 and 2003-2005 and (c) during 1993-1996, 1999-2002, and 2006-2007.

eter along-track SSH measurements for the period from October 1992 through June 2008. The merged SSH data set used in this study was taken weekly and on $1 / 3^{\circ}$ longitude Mercator grids. To maximize the signal-to-noise ratio with respect to eddy variability, the weekly SSH data is high-pass filtered with a cutoff period of 250 days.

[8] The capacity of the merged SSH data set to resolve mesoscale variability $(150-200 \mathrm{~km}$ in midlatitudes depends on how many satellite altimeters are available to generate the merged SSH data set, as demonstrated by Le Traton and Dibarboure [1999]. With two or more altimeters (this is true for all times except from December 1993 to March 1995), the SSH (geostrophic velocity) mapping error is within $10 \%$ and $20 \%$ of the signal variance, respectively. Since January 2000, when three or more satellite altimeters have been operating, the mapping errors for SSH and velocities are reduced to $5 \%$ and $10 \%$. Meanwhile, the corresponding errors became $20 \%$ and $40 \%$ from December 1993 to March 1995 when only the TOPEX/Poseidon altimeter was working.

\subsection{RMS SSH Maps}

[9] The RMS SSH map around the Hawaiian archipelago in Figure 2a is based on the high-pass filtered SSH time series from October 1992 to June 2008. The strongest eddy activity in the northwest corner of the study region is due to the variability of the Kuroshio Extension (refer to Figure 1). The second strongest is in the lee of the Hawaiian Islands due to the surface wind forcing as well as to the unstable Hawaiian Lee Countercurrent. Here, we are interested in the 
(a) EKE in Box $A\left(21-30^{\circ} \mathrm{N}, 170-150^{\circ} \mathrm{W}\right)$

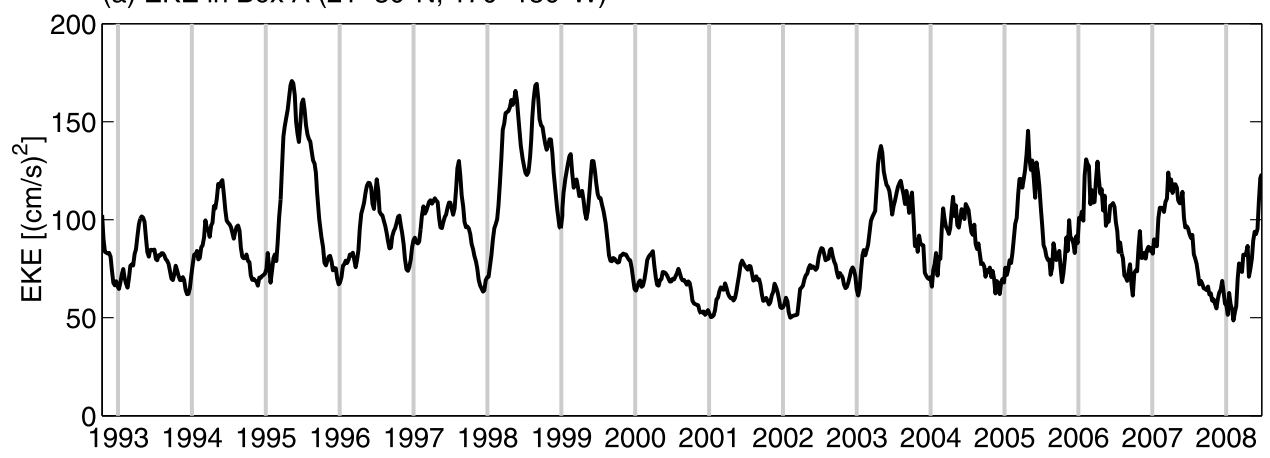

(b) EKE in Box $B\left(30-33^{\circ} \mathrm{N}, 150-140^{\circ} \mathrm{W}\right)$

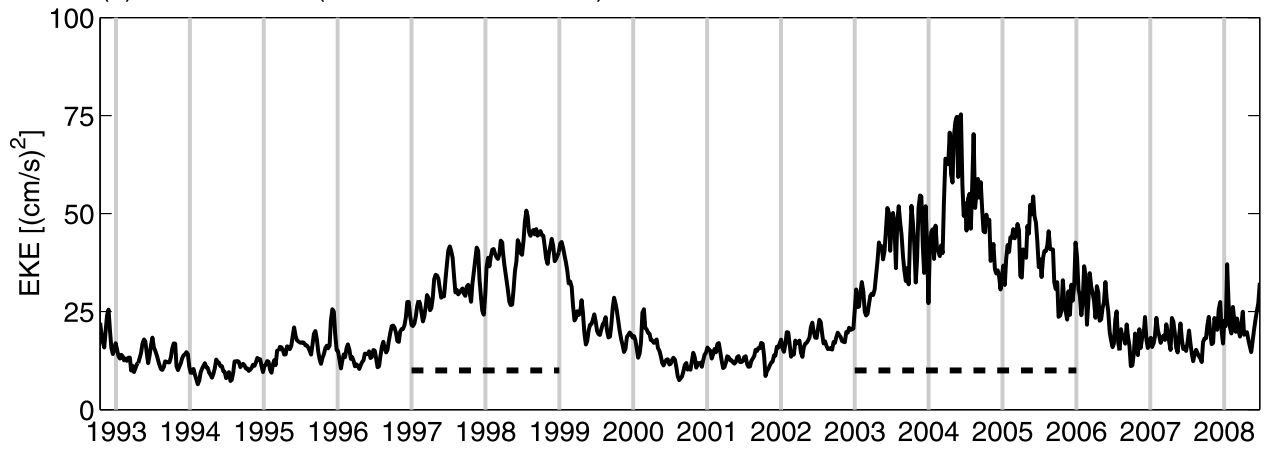

Figure 3. EKE time series in (a) box $\mathrm{A}\left(21^{\circ} \mathrm{N}-30^{\circ} \mathrm{N}, 170^{\circ} \mathrm{W}-150^{\circ} \mathrm{W}\right)$ and (b) box $\mathrm{B}\left(30^{\circ} \mathrm{N}-33^{\circ} \mathrm{N}\right.$, $\left.150^{\circ} \mathrm{W}-140^{\circ} \mathrm{W}\right)$. The dashed lines in Figure $3 \mathrm{~b}$ indicate the years experiencing elevated EKE in box $\mathrm{B}$. See Figure $2 \mathrm{a}$ for the locations of boxes A and B.

local maximum northeast of the Hawaiian archipelago. In terms of the RMS SSH amplitude, the variability northeast of the Hawaiian archipelago is about $75 \%$ of that in the lee of the Hawaiian Islands $(6 \mathrm{~cm}$ versus $8 \mathrm{~cm})$.

[10] The eddy activity northeast of the Hawaiian archipelago has large interannual variations. To illustrate this, RMS SSH variability during the strong (weak) years is shown in Figure 2b (Figure 2c) (refer to Figure 3b for the strong and weak years). During the strong years, the RMS SSH amplitude in box B is more than $4 \mathrm{~cm}$ while during the weak years it loses its local maximum feature. Figure 2c also shows that the reduction of the RMS SSH amplitude during the weak years occurs over a broad region northeast of the Hawaiian archipelago.

\subsection{EKE Time Series}

[11] Figure 3 shows the time series of the box-averaged EKE calculated from the high-pass filtered SSH anomaly $h^{\prime}$ according to geostrophy:

$$
\mathrm{EKE} \equiv \frac{g^{2}}{2 f_{0}^{2}}\left[\left(\frac{\partial h^{\prime}}{\partial x}\right)^{2}+\left(\frac{\partial h^{\prime}}{\partial y}\right)^{2}\right]
$$

where $g$ is the gravity constant and $f_{0}$ is the Coriolis parameter. The time-averaged EKE levels for boxes A and $\mathrm{B}$ are 91 and $24 \mathrm{~cm}^{2} / \mathrm{s}^{2}$, respectively. In box B (Figure $3 \mathrm{~b}$ ), the EKE signals are dominated by interannual variability, being strong during 1997, 1998, and 2003-2005. Compared to the weak years, the EKE value in the strong years in box $B$ has nearly tripled. In box A (Figure 3a), the interannual variability appears less dramatic in part because of a coexisting seasonal modulation; the annually averaged EKE level during the strong years is about twice that during the weak years.

[12] The seasonal EKE modulation in box $\mathrm{A}$ is illustrated in Figure 4, which shows a maximum in April-May and a minimum in December. The amplitude of the seasonal modulation is $17 \mathrm{~cm}^{2} / \mathrm{s}^{2}$ (one half of the peak-to-peak difference), which is about $20 \%$ of the mean $\left(91 \mathrm{~cm}^{2} / \mathrm{s}^{2}\right)$. Meanwhile, the lack of seasonal EKE modulation in box $\mathrm{B}$ is rather peculiar (Figure $3 \mathrm{~b}$ ), since seasonal modulations have been found in the NPSTCC region and in the lee of the Hawaiian Islands [Qiu, 1999; Kobashi and Kawamura, 2002].

\subsection{SSH Power Spectra}

[13] Figure 5 shows variance-preserved SSH spectra for the $3^{\circ}$ latitude by $5^{\circ}$ longitude subregions surrounding the Hawaiian archipelago. Two spectral variance peaks, one at the annual period and the other in the mesoscale range (about 90-180 days), can be found in the subregions northeast of the Hawaiian archipelago. The annual signal is stronger than those in the mesoscale range, except near the southern boundary of our study region. There is a tendency for the annual signal amplitude to increase with distance from the Hawaiian archipelago, consistent with the conclusion that the annual SSH variation maximizes $2^{\circ}-3^{\circ}$ northeast of the Hawaiian archipelago [Chen and Qiu, 2006].

[14] We define dominant periods of the mesoscale eddy activity by locating the periods at which the spectral peaks 


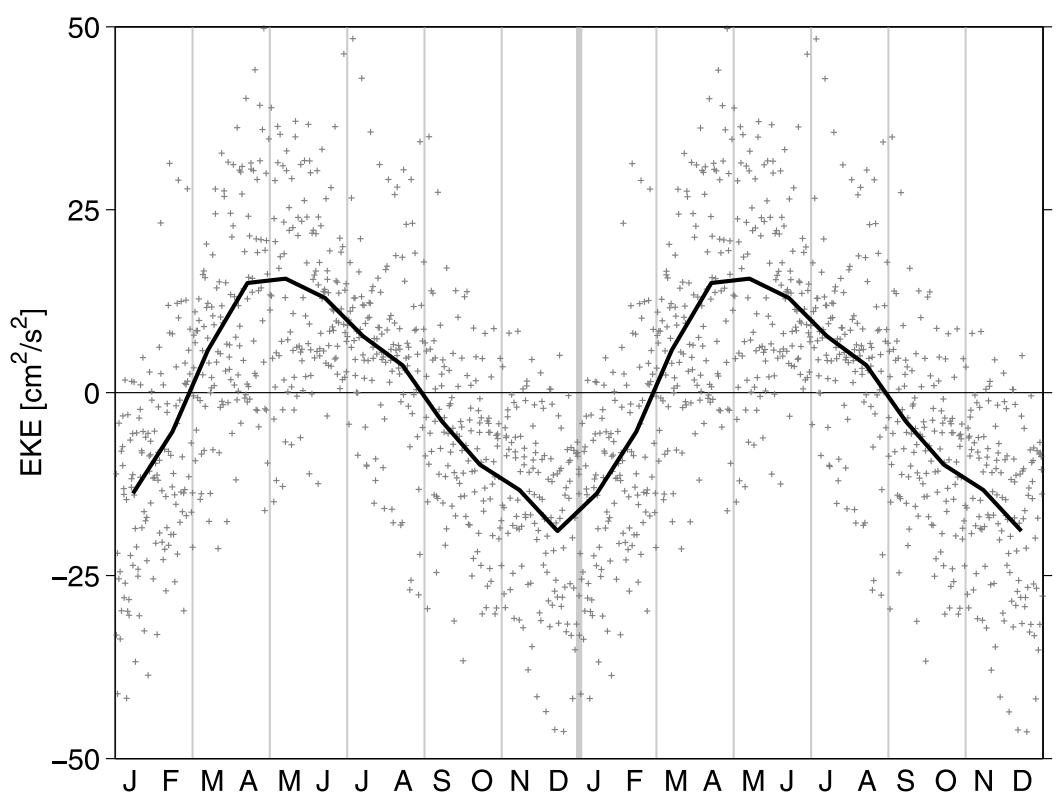

Figure 4. Seasonal EKE modulation in boxes A. The EKE time series in Figure 3a is first high-pass filtered with a cutoff period of 2 years, then sorted by months (crosses), and bin-averaged within each month (solid line).

within the mesoscale range of $90-180$ days. This definition is crude yet robust for the subregions with sharp spectral peaks like the $24^{\circ} \mathrm{N}-27^{\circ} \mathrm{N}, 160^{\circ} \mathrm{W}-155^{\circ} \mathrm{W}$ one (130 days) and the $18^{\circ} \mathrm{N}-21^{\circ} \mathrm{N}, 170^{\circ} \mathrm{W}-165^{\circ} \mathrm{W}$ one (90 days), but is also applicable to other subregions. In the lee of the island of Hawaii, 90 day oscillations dominate the mesoscale eddy activity. In the subregions between $24^{\circ} \mathrm{N}$ and $30^{\circ} \mathrm{N}$, a 130 day peak often prevails, but in the $30^{\circ} \mathrm{N}-33^{\circ} \mathrm{N}$ band,

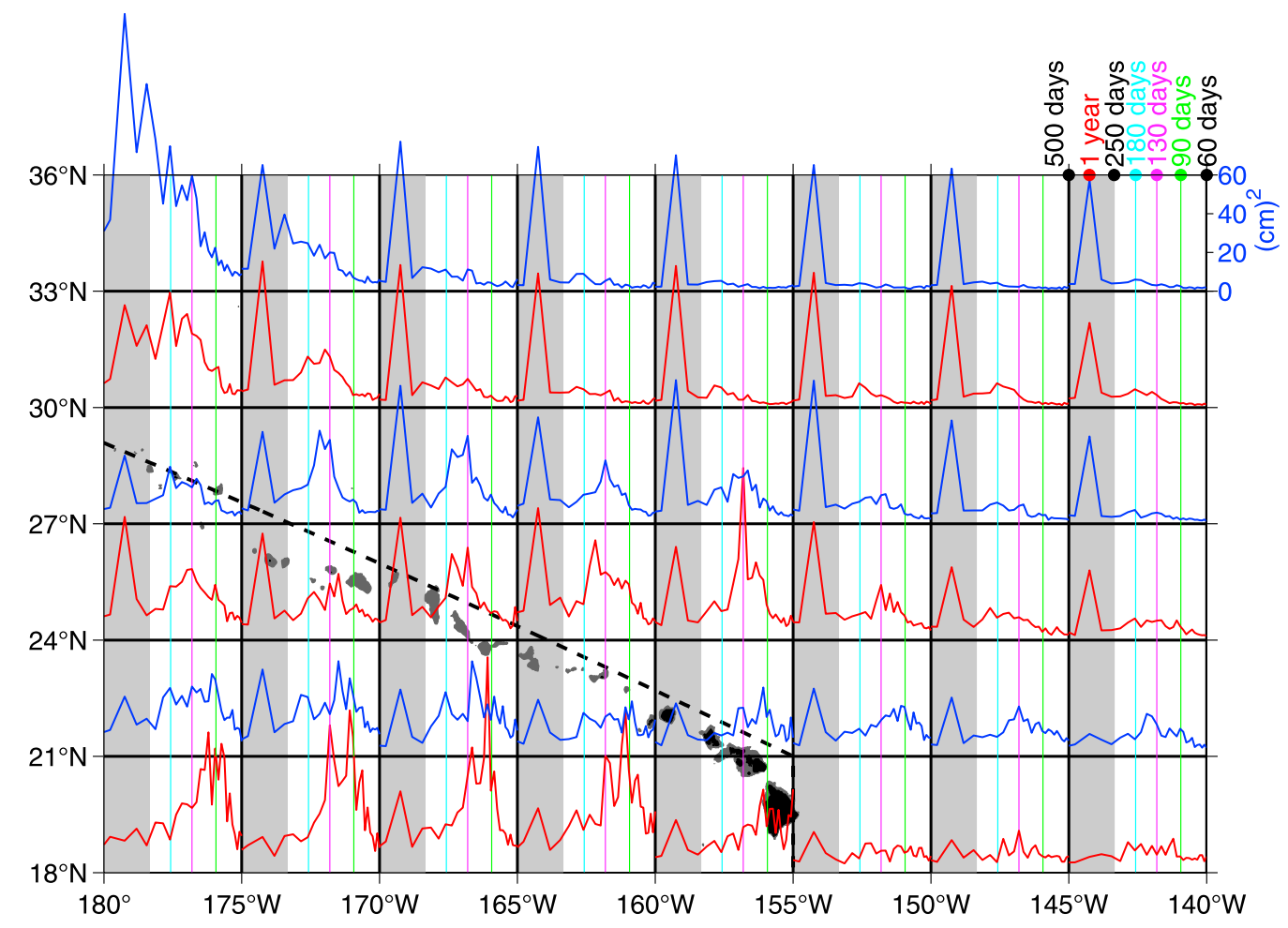

Figure 5. SSH variance-preserved spectra (red and blue curves), allocated geographically to the $3^{\circ}$ latitude by $5^{\circ}$ longitude subregions where the corresponding SSH time series are. All the plots have the same spectrum coordinate as that in the upper-right corner: the logarithmic frequency axis in $x$ with the corresponding periods from 500 days to 60 days and the linear variance axis in $y$ from 0 to $60(\mathrm{~cm})^{2}$. In each plot, periods longer than 250 days are gray shaded. Cyan, red, and green vertical lines denote periods of 180, 130, and 90 days, respectively. The dashed line highlights the Hawaiian archipelago. 
a weak 180 day peak emerges. The pattern is that the higher the latitude, the longer the dominant period.

[15] The above estimates of the dominant periods agree well with previous results. Mitchum [1995] showed 90- day oscillations in the lee of the island of Hawaii. At station A Long-term Oligotrophic Habitat Assessment (ALOHA) at $158^{\circ} \mathrm{W}$ and $22^{\circ} 45^{\prime} \mathrm{N}$ (see Figure 1 for its location), Chiswell [1996] found that mesoscale variability in dynamic height had a timescale of 100 days. Van Woert and Price [1993] detected the mesoscale variability along $25^{\circ} \mathrm{N}$ and between $154^{\circ} \mathrm{W}$ and $165^{\circ} \mathrm{W}$ with a spectral peak between 105 and 155 days. Mitchum [1996] showed that the mesoscale SSH fields northeast of the Hawaiian archipelago were dominated by the 130 day period harmonics. For the region of $23^{\circ} \mathrm{N}-30^{\circ} \mathrm{N}$ and $170^{\circ} \mathrm{W}-150^{\circ} \mathrm{W}$, Kobashi and Kawamura [2001] presented a variance spectrum that peaked at $\sim 130$ days.

\section{Baroclinic Instability Analysis: The 31/2-Layer Model}

[16] To understand the dynamics of the eddy activity northeast of the Hawaiian archipelago, baroclinic instability analysis is carried out using a $3 \frac{1}{2}$-layer QG model. Qiu [1999] used a 2/2-layer QG model for the eddy generation in the NPSTCC band, and Kobashi and Kawamura [2002] used a 3-layer QG model in the lee of the Hawaiian Islands. The $3^{1 / 2}$-layer QG model used in this study has three active layers because the vertical structure of the mean flow varies dramatically over the study region of our interest. For example (refer to Figure 9a), the mean flow at $36^{\circ} \mathrm{N}$ is eastward down to $900 \mathrm{~m}$, but it is dominantly westward at $21^{\circ} \mathrm{N}$.

[17] In the $3 \frac{1}{2}$-layer QG model, the mean state parameters are layer thickness $H_{n}\left(H_{1}=100 \mathrm{~m}, H_{2}=200 \mathrm{~m}, H_{3}=\right.$ $700 \mathrm{~m})$, velocity $\vec{U}_{n} \equiv\left\{U_{n}, V_{n}\right\} \quad(n=1,2,3)$, and density $\rho_{n}(n=1,2,3,4) . \vec{U}_{n}$ and $\rho_{n}$ are specified in each $3^{\circ}$ latitude by $5^{\circ}$ longitude subregions according to WOA05 climatology. Under the QG approximation, the linearized potential vorticity (PV) conservation equations [e.g., Pedlosky, 1998] are

$$
\left(\frac{\partial}{\partial t}+\vec{U}_{n} \cdot \nabla\right) q_{n}+J\left(\phi_{n}, \Pi_{n}\right)=0,(n=1,2,3),
$$

where

$$
\left\{\begin{array}{l}
q_{1}=\nabla^{2} \phi_{1}+F_{1}\left(\phi_{2}-\phi_{1}\right) \\
q_{2}=\nabla^{2} \phi_{2}+F_{2}\left(\phi_{1}-\phi_{2}\right)+G_{2}\left(\phi_{3}-\phi_{2}\right) \\
q_{3}=\nabla^{2} \phi_{3}+G_{3}\left[\phi_{2}-(1+\gamma) \phi_{3}\right]
\end{array}\right.
$$

and $J$ is the Jacobian operator. In above equations, $\Pi_{n}$ is the mean PV in layer $n, q_{n}$ and $\phi_{n}$ are the perturbation PV and stream function, $g_{j i}^{\prime}=g \frac{\left(\rho_{j}-\rho_{i}\right)}{\rho_{0}}, F_{i}=\frac{f_{0}^{2}}{g_{21}^{\prime} H_{i}}(i=1,2), G_{i}=$ $\frac{f_{0}^{2}}{g_{32}^{\prime} H_{i}}(i=2,3)$, and $\gamma=\frac{\rho_{4}-\rho_{3}}{\rho_{3}-\rho_{2}}$, where $f_{0}, g$, and $\rho_{0}$ are the Coriolis parameter, the gravitational acceleration, and the reference seawater density, respectively. Assuming $\phi_{n}$ takes the waveform, i.e.,

$$
\phi_{n}=A_{n} e^{i(k \cdot x+l \cdot y-\omega \cdot t)},
$$

where $(k, l)$ are the wave numbers and $\omega$ is the frequency, and denoting $K^{2}=k^{2}+l^{2}, U_{n s}=U_{n} \cdot k+V_{n} \cdot l$, and $\Pi_{n s}=$ $\Pi_{n y} \cdot k-\Pi_{n x} \cdot l$, we have from equation (1)

$$
\begin{cases}\left(-\omega+U_{1 s}\right)\left[-\left(K^{2}+F_{1}\right) A_{1}+F_{1} A_{2}\right] & +\Pi_{1 s} A_{1}=0 \\ \left(-\omega+U_{2 s}\right)\left[-\left(K^{2}+F_{2}+G_{2}\right) A_{2}+F_{2} A_{1}+G_{2} A_{3}\right] & +\Pi_{2 s} A_{2}=0 \\ \left(-\omega+U_{3 s}\right)\left[-\left(K^{2}+(1+\gamma) G_{3}\right) A_{3}+G_{3} A_{2}\right] & +\Pi_{3 s} A_{3}=0 .\end{cases}
$$

Equation (3)'s determinant must be zero to ensure nonzero solutions for $A_{i}(i=1,2,3)$. This results in a cubic equation for $\omega$. A wave is deemed unstable when the imaginary part of $\omega, \omega_{i}$, is positive so that $\phi_{n}$ increases with $e^{\omega_{i} t}$. The positive $\omega_{i}$ value is called the growth rate of the unstable wave.

[18] To derive an eddy energy equation for the unstable waves, we rewrite $\phi_{n}=A_{n}(t) e^{i(k \cdot x+l \cdot y)}$. Then the first equation in equation (3) in this case becomes

$$
\left(\frac{\partial}{\partial t}+i \cdot U_{1 s}\right)\left[-\left(K^{2}+F_{1}\right) A_{1}+F_{1} A_{2}\right]+i \cdot \Pi_{1 s} A_{1}=0 .
$$

Applying the operation $\frac{h_{1}}{2}$ [(equation (4)) $\cdot A_{1}^{*}+$ (equation $(4))^{*} A_{1}$ ], where * stands for complex conjugate, yields the eddy energy equation for the first layer. By deriving similar equations for the second and third layers, we have the following eddy energy equation for the whole water column:

$$
\begin{aligned}
\frac{\partial}{\partial t}\{ & \frac{K^{2}}{2}\left(h_{1} A_{1} A_{1}^{*}+h_{2} A_{2} A_{2}^{*}+h_{3} A_{3} A_{3}^{*}\right)+\frac{f_{0}^{2}}{2 g_{21}^{\prime}}\left(A_{1}-A_{2}\right)\left(A_{1}^{*}-A_{2}^{*}\right) \\
& \left.+\frac{f_{0}^{2}}{2 g_{32}^{\prime}}\left(A_{2}-A_{3}\right)\left(A_{2}^{*}-A_{3}^{*}\right)+\gamma \frac{f_{0}^{2}}{2 g_{32}^{\prime}} A_{3} A_{3}^{*}\right\} \\
= & i \frac{f_{0}^{2}}{2 g_{21}^{\prime}}\left(U_{1 s}-U_{2 s}\right)\left(A_{2} A_{1}^{*}-A_{2}^{*} A_{1}\right) \\
& +i \frac{f_{0}^{2}}{2 g_{32}^{\prime}}\left(U_{2 s}-U_{3 s}\right)\left(A_{3} A_{2}^{*}-A_{3}^{*} A_{2}\right) .
\end{aligned}
$$

For unstable waves, the right-hand side of equation (5) must be positive so that the eddy energy increases with time. Note that, from one subregion to another meridionally, it is $f_{0}$ and not its meridional gradient $(\beta)$ that appears in the eddy energy equation. Equation (5) suggests that the eddy energy tends to increase faster for larger $f_{0}$ (toward north), stronger vertical shear, and weaker stratification (that is, $g_{21}^{\prime}$ and $g_{32}^{\prime}$ are smaller).

[19] The mean state parameters, $\vec{U}_{n}$ and $\rho_{n}$, are the arithmetic averages of the WOA05 climatologies over the $3^{\circ}$ latitude by $5^{\circ}$ longitude subregions and within the respective layers. Since the study region is located in the eastern part of the subtropical gyre, the mean velocities $\vec{U}_{n}$ are a few $\mathrm{cm} / \mathrm{s}$ in magnitude and are eastward in the north of the study region but westward in the south (Figure 6a). Near the surface the flow switches direction at about $24^{\circ} \mathrm{N}$, while in the second and third layers, this occurs at about $27^{\circ} \mathrm{N}$ and $33^{\circ} \mathrm{N}$, respectively. Also in each subregion, the mean flow rotates clockwise with increasing depth, exhibiting the $\beta$-spiral pattern. Both of these features are manifestations of the wind-driven subtropical gyre, which retreats northwestward when going deeper [e.g., Pedlosky, 1998]. 

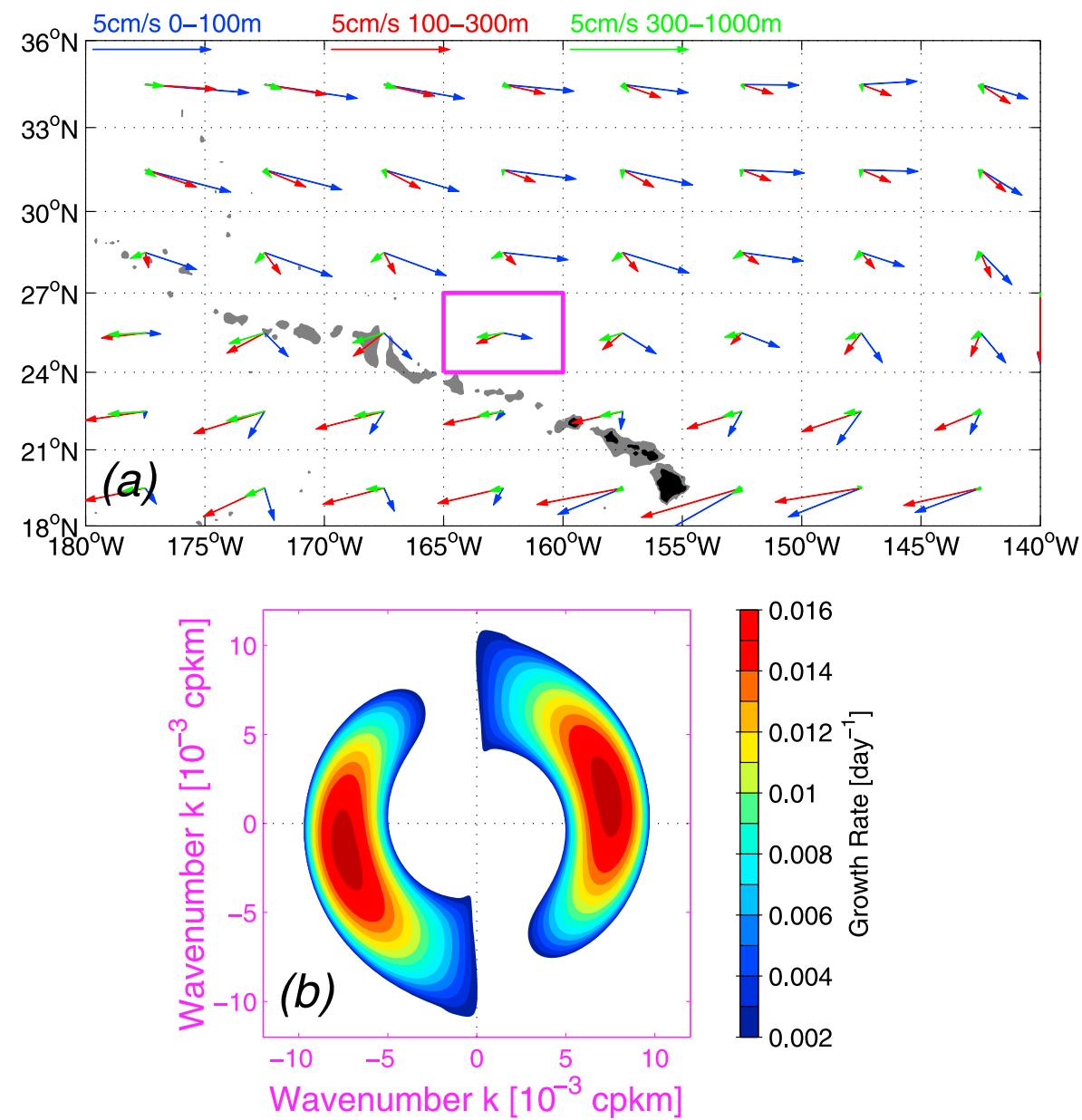

Figure 6. (a) WOA05 geostrophic velocities (referenced to $1500 \mathrm{~m})$, averaged within the first $(0-100 \mathrm{~m}$, blue), second $\left(100-300 \mathrm{~m}\right.$, red), and third $\left(300-1000 \mathrm{~m}\right.$, green) layers and over the $3^{\circ}$ latitude by $5^{\circ}$ longitude subregions. Vector labels are at the top of Figure 6a. (b) Growth rates of the unstable waves from the $3 \frac{1}{2}$-layer model. The mean velocities are from the $24^{\circ} \mathrm{N}-27^{\circ} \mathrm{N}, 165^{\circ} \mathrm{W}-160^{\circ} \mathrm{W}$ subregion which is highlighted by the purple box in Figure $6 \mathrm{a}$.

[20] Inputting the mean state parameters in $24^{\circ} \mathrm{N}-27^{\circ} \mathrm{N}$, $165^{\circ} \mathrm{W}-160^{\circ} \mathrm{W}$ subregion into equation (3), we obtained the growth rates of unstable waves $\omega_{i}$ as functions of wave numbers $(k, l)$ (Figure 6b). With $\omega_{i}>0$, perturbations $\phi_{n}$ grow with $e^{\omega_{i} t}$ (refer to equation (2)). Thus, the growth rates are indicative of the strength of baroclinic instability in its initial stage and are likely proportional to the regional EKE level.

[21] In Figure $6 b$, the maximum growth rate is $0.0168 \approx$ $1 / 60 \mathrm{~d}^{-1}$ at $(k, l)=(7.4,1.6) \times 10^{-3}$ cycle per $\mathrm{km}(\mathrm{cpkm})$, which equals a total wavelength of $132 \mathrm{~km}$. Since the unstable wave with the maximum growth rate likely grows to be dominant, its e-folding timescale $\omega_{i}^{-1}, O(60)$ days, approximates the time elapse for initial perturbations to grow to finite amplitude eddies. Meanwhile, we note that the wavelength associated with the fastest growing unstable wave is significantly shorter than the observed wavelengths, which are $O(500) \mathrm{km}$ based on the longitude-time Hovmoller diagram of the $\mathrm{SSH}$ anomalies along $26^{\circ} \mathrm{N}$ east of the Hawaiian archipelago. Because the observed SSH is a fully developed eddy field, the present linear stability analysis cannot address the difference between the wavelengths of unstable waves and those in the observations. However, the numerical study by Halliwell et al. [1994] has shown that the energy spectrum peak shifts from initial wavelengths of $150-200 \mathrm{~km}$ of the most unstable waves to $500-1000 \mathrm{~km}$ of the eddy fields after 1 year.

[22] Northeast of the Hawaiian archipelago (Figure 7), the fastest-growing unstable waves, with growth rates of $0.01-$ $0.02 \mathrm{~d}^{-1}$ and wavelengths of $\sim 150 \mathrm{~km}$, are found in $24^{\circ} \mathrm{N}-$ $27^{\circ} \mathrm{N}, 170^{\circ} \mathrm{W}-155^{\circ} \mathrm{W}$ region, where the RMS SSH variability is enhanced. The growth rates, $\omega_{i}$, of $0.01-0.02 \mathrm{~d}^{-1}$ in the eddy-rich subregions indicate that initial small disturbances likely take about 50-100 days, or 2-3 months, to grow to finite amplitudes. We also note that the $(k, l)$ ranges for unstable waves (color-shaded area in Figure 7) tend to be broader in the subregions where the unstable waves grow faster.

[23] The intensity of baroclinic instability in each $3^{\circ}$ latitude by $5^{\circ}$ longitude subregion can be quantified by the maximum growth rate over the entire $(k, l)$ space. Figure 7 shows that the intensity pattern matches well geographically with the level of the observed SSH variability. 


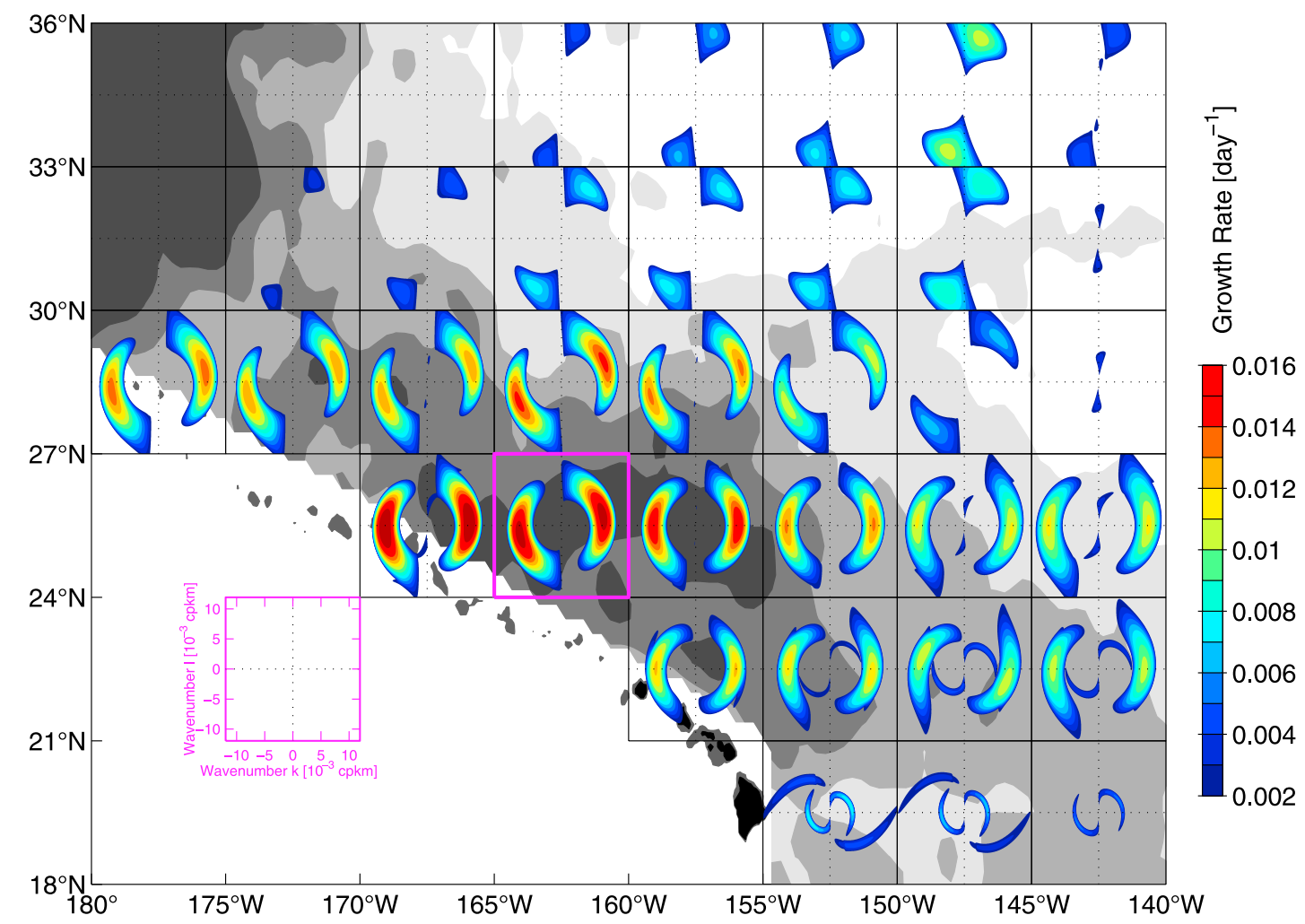

Figure 7. Growth rates of the unstable waves from the $3 \frac{1}{2}$-layer model, allocated geographically according to where the mean state parameters are. All plots use the same color scales on the right side and the same wave number coordinate as that in the low-left corner (purple) and as that in Figure 6b. Northeast of the Hawaiian archipelago, the lightest gray shading shows where the RMS SSH amplitude $\geq 3 \mathrm{~cm}$, and the darker ones are for 4, 5, and $6 \mathrm{~cm}$, respectively (see Figure 2a for the color shading of the RMS SSH amplitude).

\subsection{Spatial Variation of the Growth Rate}

[24] The good match between the strength of baroclinic instability and the observed SSH variability in Figure 7 motivates us to investigate which mean state parameters are responsible for the strongest instability in the $24^{\circ} \mathrm{N}-27^{\circ} \mathrm{N}$, $170^{\circ} \mathrm{W}-155^{\circ} \mathrm{W}$ area northeast of the Hawaiian archipelago, and why the instability outside the $24^{\circ} \mathrm{N}-27^{\circ} \mathrm{N}$ and $170^{\circ} \mathrm{W}-155^{\circ} \mathrm{W}$ area is relatively weak.

[25] The zonal variation in the strength of the instability along $24^{\circ} \mathrm{N}-27^{\circ} \mathrm{N}$ is first investigated. As shown in Figure 8a, the westward $u_{g}$ in the main thermocline gradually weakens toward the east. As a result, the difference of the zonal velocities between the first and second layers $\left(u_{g 1}-u_{g 2}\right)$ decreases from 2.5 to $1.2 \mathrm{~cm} / \mathrm{s}$ eastward. Figure $8 \mathrm{~b}$ shows that $v_{g}$ does not vary noticeably, but Figure 8c shows that the stratification weakens eastward $\left(g_{21}^{\prime}\right.$ decreases from 0.013 to $0.009 \mathrm{~kg} / \mathrm{m}^{3}$ ).

[26] We isolated each factor (e.g., $u_{g}$ among $u_{g}, v_{g}$, and $\rho$ ) by varying the factor $\left(u_{g}\right)$ zonally following the WOA05 climatology while fixing the others $\left(v_{g}\right.$ and $\left.\rho\right)$ to those at the subregion of $24^{\circ} \mathrm{N}-27^{\circ} \mathrm{N}, 160^{\circ} \mathrm{W}-155^{\circ} \mathrm{W}$. Figure $8 \mathrm{~d}$ shows that, toward the east, varying $u_{g}$ results in a sharp decrease in the strength of the instability, while varying $\rho$ results in an increase in the strength. This is consistent with equation (5). Weaker vertical shears (i.e., smaller $U_{1 s}-U_{2 s}$ due to the weakening of the zonal flow in the main thermocline) make the right-hand side of equation (5) smaller but weaker stratification (i.e., smaller $g_{21}^{\prime}$ and $g_{32}^{\prime}$ ) makes the right-hand side of equation (5) larger.

[27] The situation in the meridional direction is displayed in Figure 9. Along $160^{\circ} \mathrm{W}-155^{\circ} \mathrm{W}$ (Figure 9a), the vertical structure of the zonal flow varies significantly: in the north, the flow is almost uniformly eastward but in the south the westward flow in the subsurface dominates the water column. The vertical shear thus increases from the north to the south $\left(u_{g 1}-u_{g 2}\right.$ increases from 1.2 to $\left.2.1 \mathrm{~cm} / \mathrm{s}\right)$. Figure $9 \mathrm{c}$ shows that the stratification also strengthens southward $\left(g_{21}^{\prime}\right.$ increases from 0.008 to $\left.0.014 \mathrm{~kg} / \mathrm{m}^{3}\right)$. As shown in Figure $9 \mathrm{~d}$, north of the reference latitudes $\left(24^{\circ} \mathrm{N}-27^{\circ} \mathrm{N}\right) u_{g}$ is the dominant factor, weakening the baroclinic instability, while the stratification and $f_{0}$ values act adversely. South of the reference latitudes, both the stratification and the $f_{0}$ factors make the baroclinic instability weaker, while the $u_{g}$ factor enhances the baroclinic instability.

[28] In summary, the reason for the decreasing baroclinic instability eastward and northward is the weakening of the vertical shear of the zonal flow. The reason for the decreasing instability southward is the strengthening of stratification and reduction in the Coriolis parameter.

\subsection{Seasonal Variation of the Growth Rate}

[29] The impact of the seasonally varying mean state parameters on the growth rate is investigated by adopting WOA05 monthly climatology in the 3/2-layer QG model. Here, we present the results for the $24^{\circ} \mathrm{N}-27^{\circ} \mathrm{N}, 165^{\circ} \mathrm{W}-$ 

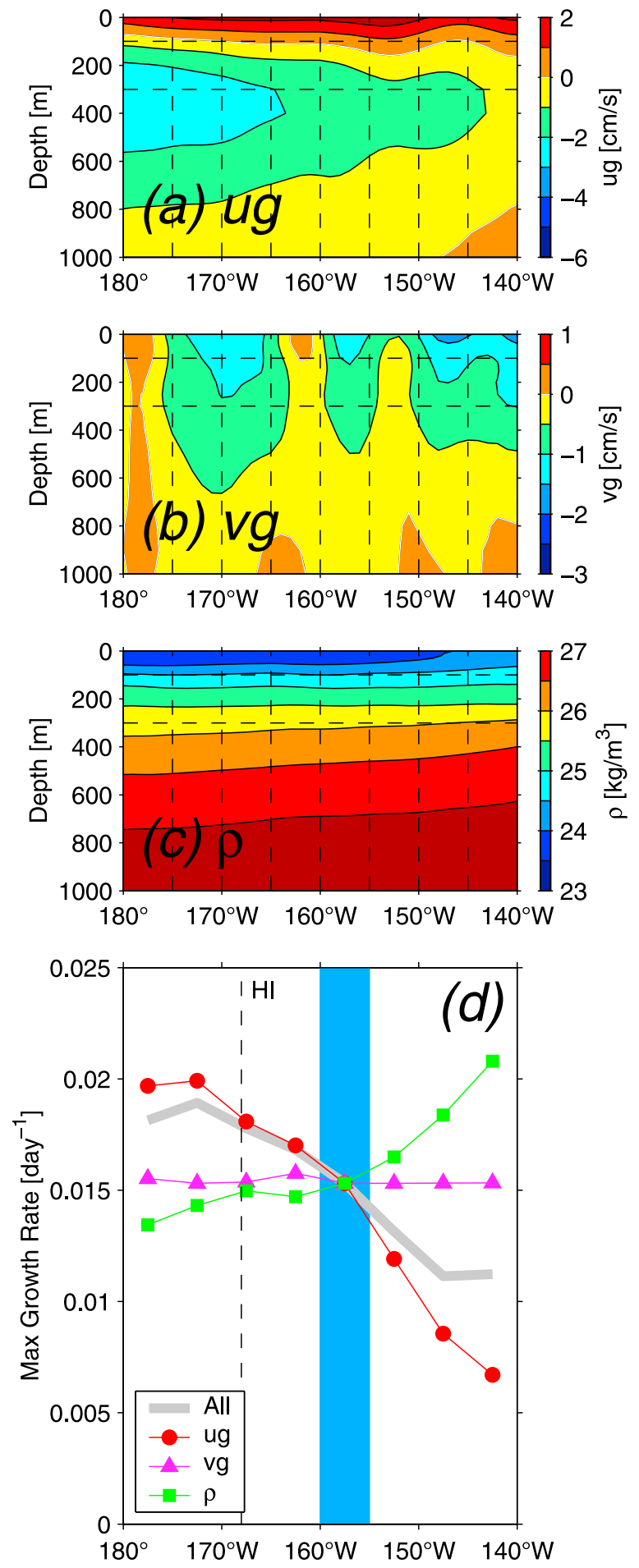

Figure 8. (a, b) WOA05 zonal and meridional velocities $\left(u_{g}\right.$ and $\left.v_{g}\right)$, referenced to $1500 \mathrm{~m}$ and averaged between $24^{\circ} \mathrm{N}$ and $27^{\circ} \mathrm{N}$. (c) WOA05 density $\rho$ averaged between $24^{\circ} \mathrm{N}$ and $27^{\circ} \mathrm{N}$. In Figures $8 \mathrm{a}-8 \mathrm{c}$, the horizontal dashed lines show the three layers and the vertical ones the $5^{\circ}$ longitude subregions. (d) Maximum growth rates of the unstable waves over the entire $(k, l)$ space. To obtain the thick gray line, all $u_{g}, v_{g}$, and $\rho$ vary with longitudes. For the red line, $u_{g}$ varies but the others $\left(v_{g}\right.$ and $\left.\rho\right)$ are fixed to the values at $160^{\circ} \mathrm{W}-155^{\circ} \mathrm{W}$ indicated by the blue strip. The same is applied to the purple (green) line for $v_{g}(\rho)$. $160^{\circ} \mathrm{W}$ subregion, in which the monthly mean velocities and stratification are shown in Figure 10. Neither the zonal nor the meridional velocities have significant seasonal variations (Figures 10a and 10b), but the seasonal variation is substantial in the first layer density due to summer
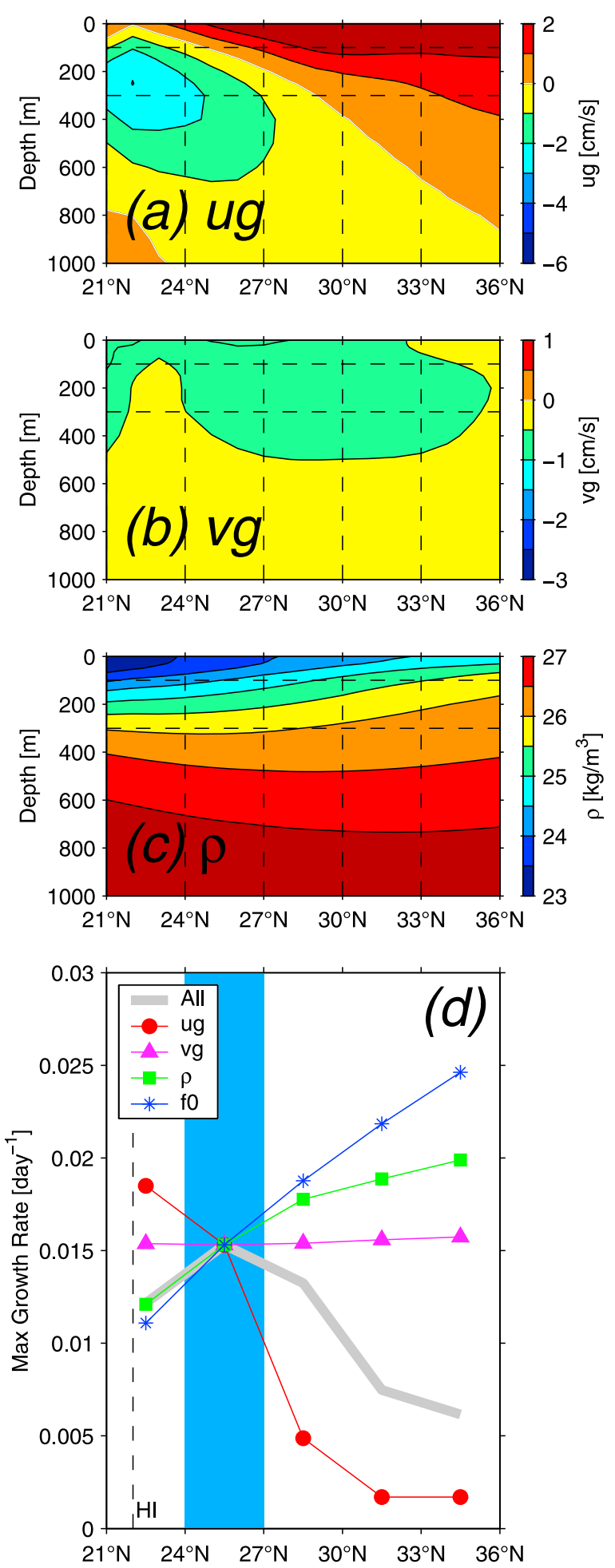

Figure 9. (a-d) Same as Figure 8, except that $u_{g}, v_{g}$, and $\rho$ are functions of latitudes and averaged between $160^{\circ} \mathrm{W}$ and $155^{\circ} \mathrm{W}$, and that in Figure $9 \mathrm{~d}$ the effect of the Coriolis parameter $f_{0}$ is added. 

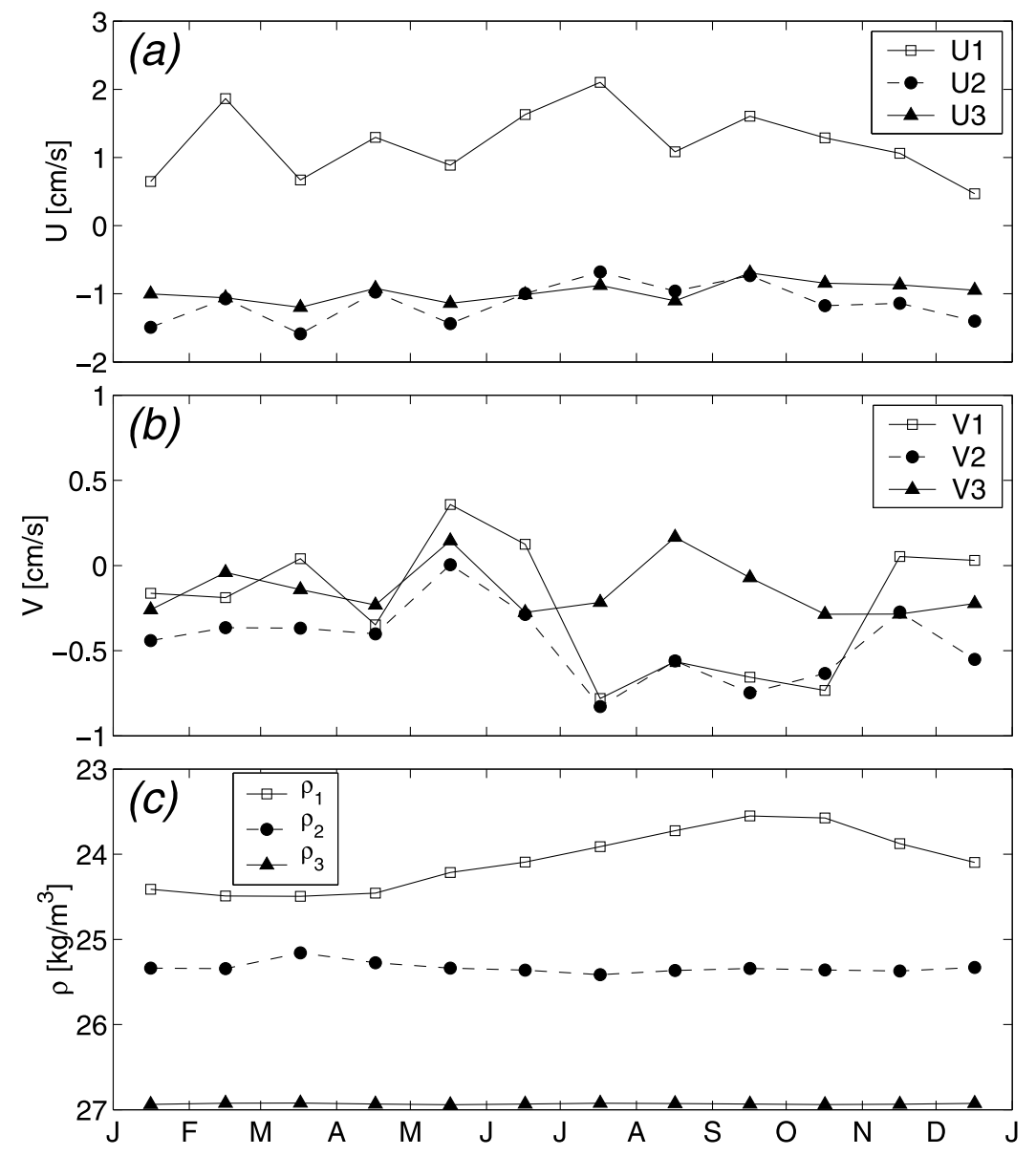

Figure 10. (a) WOA05 monthly zonal velocities, referenced to $1500 \mathrm{~m}$ and averaged over the $24^{\circ} \mathrm{N}-$ $27^{\circ} \mathrm{N}, 165^{\circ} \mathrm{W}-160^{\circ} \mathrm{W}$ subregion and within the three layers: $0-100 \mathrm{~m}\left(U_{1}\right), 100-300 \mathrm{~m}\left(U_{2}\right)$, and $300-$ $1000 \mathrm{~m}\left(U_{3}\right)$. (b, c) Same as Figure 10a but for the meridional velocities and densities, respectively.

heating and winter cooling at the surface (Figure 10c). With the vertical shear being approximately constant, strongest baroclinic instability can be expected in late winter (February and March) when the stratification is weakest $\left(\rho_{2}-\rho_{1}\right.$ is smallest in Figure 10c). Figure 11a shows that the strength of baroclinic instability (i.e., the maximum growth rate) peaks in February-March.

[30] Two additional calculations are presented in Figure 11a. When the velocities vary monthly and the densities are held constant at their annual mean values, the growth rate does not show a clear seasonal cycle, except for a weak February peak (see the solid gray line in Figure 11a). On the other hand, when the densities vary monthly and the velocities are held constant, a clear seasonal cycle with a peak in March is seen. The seasonal variation in the instability strength is therefore due to the seasonal variation in the first layer density.

[31] Figure $11 \mathrm{~b}$ shows that the seasonal variation of the growth rate closely matches that of the EKE, with a $2-$ 3 month lead. Similar leads were detected in other regions such as the NPSTCC band [Qiu, 1999] and the lee of the Hawaiian Islands [Kobashi and Kawamura, 2002]. With the wintertime growth rate ranging from 0.02 to $0.03 \mathrm{~d}^{-1}$ (Figure 11a), this 2-3 month lead time can be interpreted as the time required for initial disturbances to fully grow to finite-amplitude anomalies. Combined with the spatial match between the instability growth rate and the RMS SSH signals (Figure 7), this temporal match suggests that baroclinic instability of the vertically sheared, regional mean circulation provides the energy source for the enhanced eddy variability northeast of the Hawaiian archipelago.

\section{Discussion on Causes for the EKE Interannual Variabilities}

[32] Relationships between altimetric EKE interannual variations and the regional large-scale atmosphere forcing have been identified in several parts of the world oceans. Making use of high-resolution numerical simulations, Penduff et al. [2004] and Meredith and Hogg [2006] attributed the observed EKE interannual variations in the North Atlantic and in the Southern Ocean to the interannual variations in the regional wind forcing, which are quantified by the North Atlantic Oscillation (NAO) and Southern Annular Model (SAM) indies, respectively. Similarly but based on the observational data sets, Qiu and Chen [2010] showed the connection between the EKE interannual variations in the North Pacific STCC region and the Western Pacific (WP) index. The argument is as follows: the largescale, interannually varying wind forcing modifies the mean 

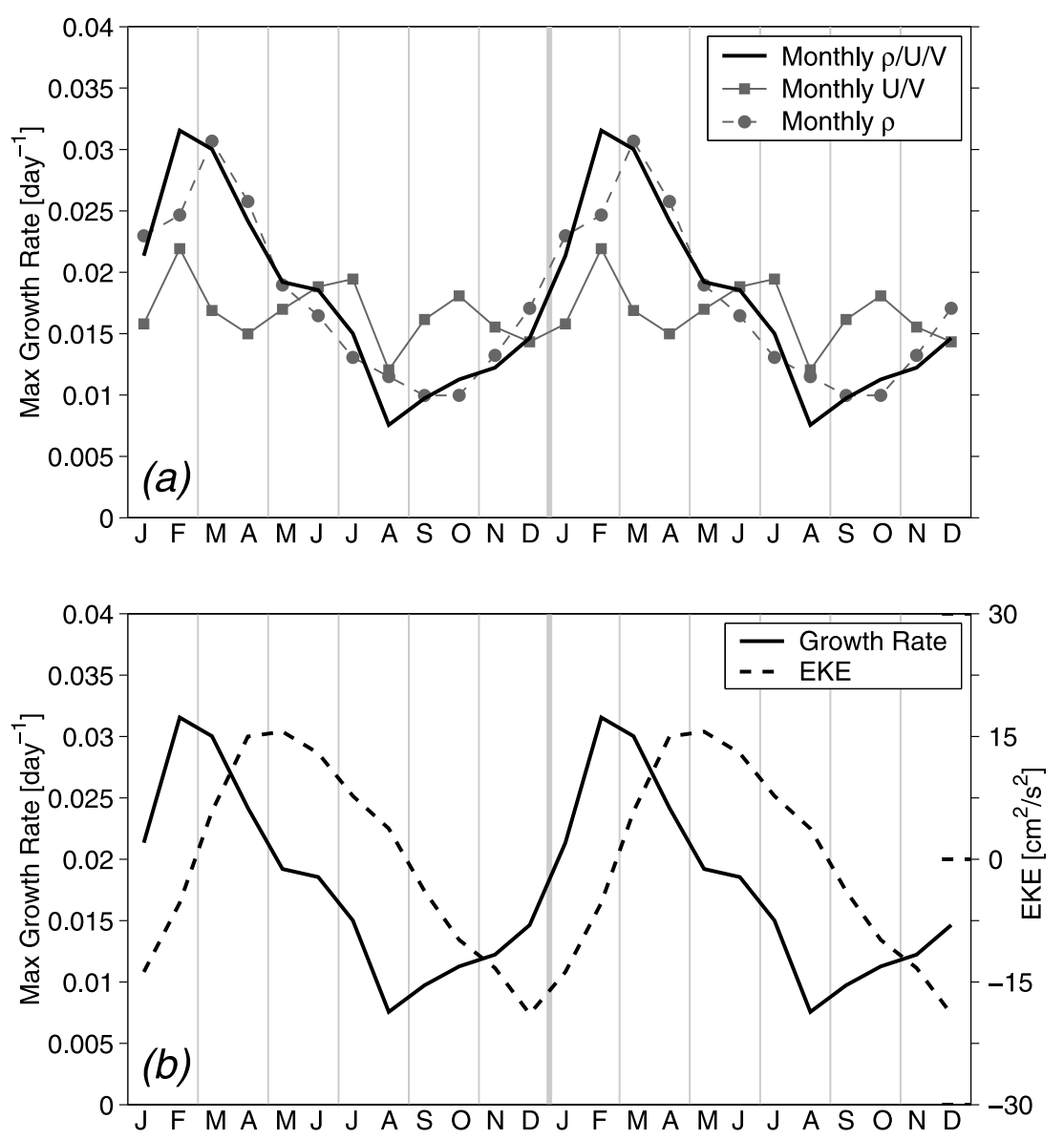

Figure 11. (a) Seasonal cycle of the growth rates (black line) in the $24^{\circ} \mathrm{N}-27^{\circ} \mathrm{N}, 165^{\circ} \mathrm{W}-160^{\circ} \mathrm{W}$ subregion by using the monthly $u_{g}, v_{g}$, and $\rho$ (Figure 10) in the baroclinic instability analysis. To obtain the gray line with squares (circles), we used monthly $u_{g}$ and $v_{g}(\rho)$ but annual $\rho\left(u_{g}\right.$ and $\left.v_{g}\right)$. (b) The maximum growth rate (thick black line) is the same as that in Figure 11a. The dashed line shows the seasonal EKE modulation in box A and is the same as the thick line in Figure 4 (scale on the right).

circulation, and thus its baroclinic instability properties which change the EKE levels on the interannual timescales.

[33] A significant correlation also exists between the EKE interannual variations northeast of the Hawaiian archipelago and the PDO index [Mantua et al., 1997], which is the amplitude of the first Empirical Orthogonal Function (EOF) mode of the monthly SST anomalies in the North Pacific Ocean. In Figure 12a (Figure 12b), the zero-lag correlation between the EKE interannual variations in box $\mathrm{A}(\mathrm{B})$ and the PDO index is $0.38(0.27)$. When the PDO index leads 14 (10) months, the correlation reaches the maximum at $0.67(0.41)$.

[34] The PDO index associates not only with a SST pattern in the North Pacific but also with a large-scale SSH pattern. As having been noticed by Cummins et al. [2005], there is an excellent correspondence between the PDO index and the first EOF mode amplitude of the largescale SSH in the northeast Pacific. In Figure 13b, the zerolag correlation between the mode amplitude and the PDO index is 0.86 . This is because, as demonstrated by Chhak et al. [2009] using an ocean model, the primary dynamical ingredient of the PDO index is the anomalous Ekman flow associated with the Aleutian Low. The anomalous Ekman flow advects mean SST to generate the SST anomaly associated with the PDO index. At the same time, the convergence of the anomalous Ekman flow, i.e., Ekman pumping, heaves the thermocline depth which is then reflected in the SSH anomaly. Figure $13 \mathrm{~b}$ also indicates a time lag, which is not clear in the work of Cummins et al. [2005]. The correlation increases moderately to 0.89 when the SSH mode lags 3 months.

[35] The large-scale SSH spatial pattern associated with the PDO index (Figure 13a) is most relevant to the present study. During the positive phase of the PDO index, for example, in 2003-2005, anomalous northeastward surface geostrophic flow in our study region is inferred by assuming geostrophy. According to the numerical model results of Chhak et al. [2009], the anomalous northeastward flow is trapped in the upper layer, and thus increases eastward vertical shear of the mean flow between the upper layer and the thermocline. As pointed out in section 3 (see Figures $8 \mathrm{a}$ and $8 \mathrm{~d}$ ), when the eastward vertical shear increases, the baroclinic instability becomes stronger, elevating the EKE levels with lags of several months. This scenario is consistent with Figures $12 \mathrm{a}$ and $12 \mathrm{~b}$. The lags between the PDO index and the EKE time series are argued as the time for the mean flow to adjust to the anomalous 

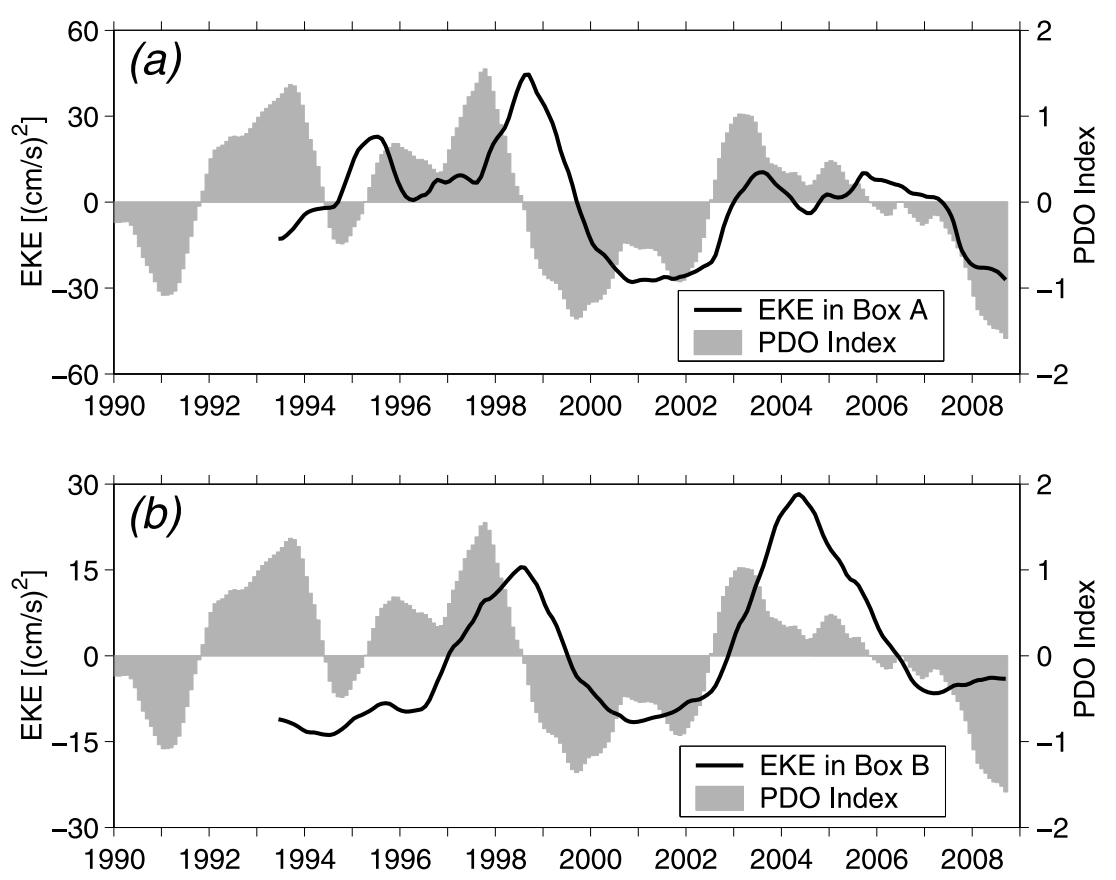

Figure 12. Comparison between the PDO index (gray shading and its scale on the right) and the EKE time series (a) in box A and (b) in box B. The PDO index was downloaded from http:// jisao.washington.edu/pdo/PDO.latest. A 1 year running average is applied to both the PDO index and the EKE time series to emphasize the interannually variabilities. The corresponding weekly EKE time series with means are shown in Figure 3.
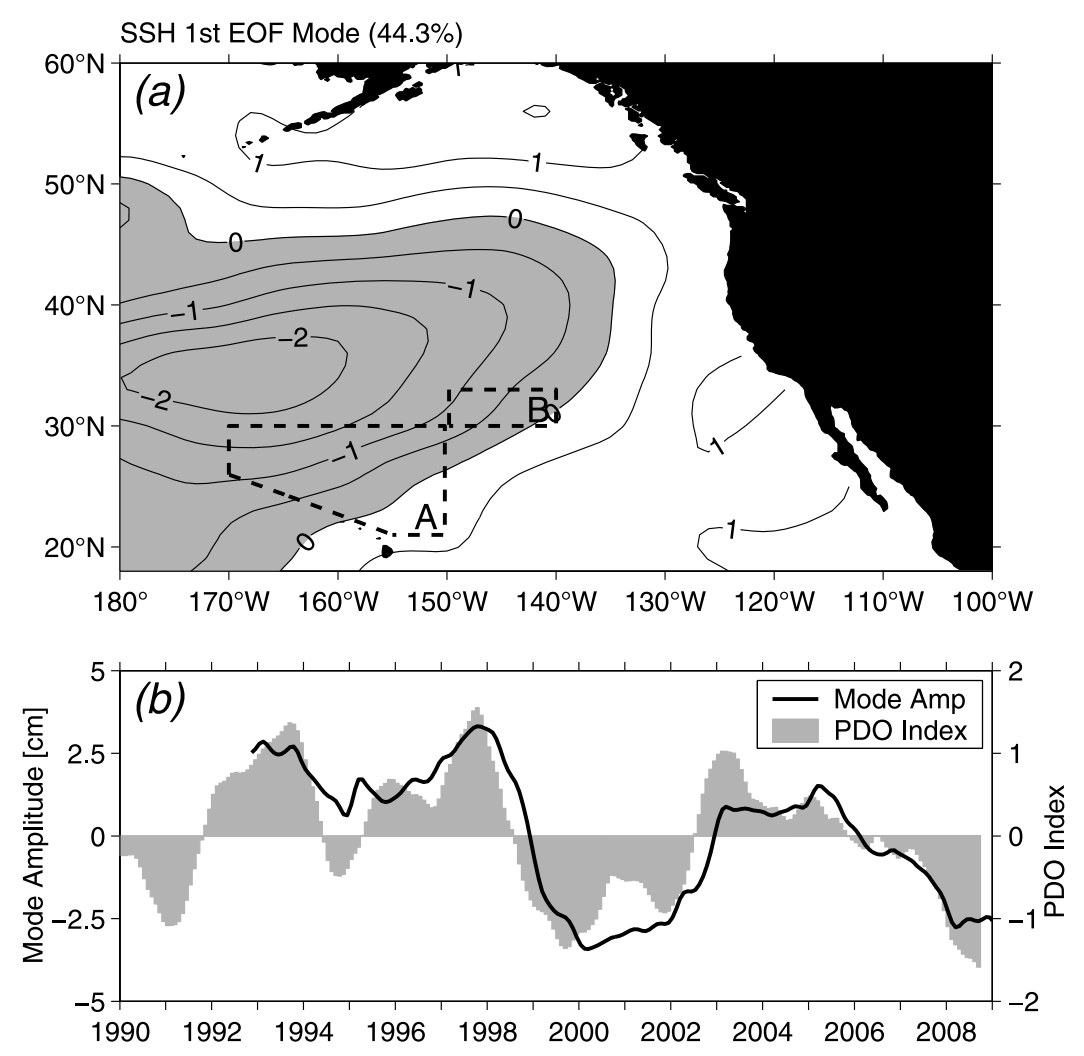

Figure 13. (a) Spatial pattern and (b) mode amplitude of the first EOF mode of the SSH anomalies in the northeast Pacific. The monthly SSH anomaly fields are first formed and the monthly climatology is then subtracted. The SSH fields are then mapped into 2 by 2 degree grids using the Gaussian decay scale of $3^{\circ}$ in longitude and latitude. In Figure 13a, boxes A and B are the same as those in Figure 2a. In Figure 13b, the PDO index (scale on the right) is the same as those in Figure 12. 
Ekman pumping and for the eddies resulted from baroclinic instability to grow to their finite amplitudes.

\section{Summary}

[36] Ocean surface eddy activity northeast of the Hawaiian archipelago was described on the basis of the long-term satellite altimetric SSH measurements from Ocober 1992 to June 2008. In the strong EKE years of 1997-1998 and $2003-2005$, the annually averaged EKE levels are doubled and tripled in box A (adjacent to the Hawaiian archipelago along $\sim 26^{\circ} \mathrm{N}$ ) and box B (farther northeastward along the STF zone at $\sim 32^{\circ} \mathrm{N}$ ), respectively. The amplitude of the seasonal EKE modulation in box A is about $20 \%$ of the mean: 17 versus $91 \mathrm{~cm}^{2} / \mathrm{s}^{2}$. The spectral analysis in the $3^{\circ}$ latitude by $5^{\circ}$ longitude subregions reveals the dominant mesoscale periods ranging from 90 days near $18^{\circ} \mathrm{N}$ to 180 days near $36^{\circ} \mathrm{N}$.

[37] By specifying the mean oceanic state from WOA05 annual climatology, we performed a baroclinic instability analysis on the regional mean flows by adopting the $3 \frac{1}{2}$-layer QG model. The analysis revealed that the intensity of the instability varies spatially, and its pattern matches well with the observed level of eddy activity northeast of the Hawaiian archipelago. The sensitivity study of the mean flow parameters shows that the instability intensity decreases eastward and northward because of the weakening of the vertical shear of the zonal flow and decreases southward because of the strengthening of stratification and reduction in the Coriolis parameter. With WOA05 monthly climatology, the $3 \frac{1}{2}$-layer QG model produced a seasonal cycle of the growth rate that peaks in February-March. This seasonal cycle is largely determined by the seasonal variation of density in the top $100 \mathrm{~m}$. The modeled seasonally varying growth rate signal leads the observed seasonal modulation in EKE by $2-3$ months; this $2-3$ month elapse is considered as the time required for initial disturbance to grow into finite-amplitude eddies. The spatial match between the instability growth rate and the observed RMS SSH variability and the temporal match between the seasonally varying instability strength and the observed seasonal EKE modulation suggest that baroclinic instability by the vertically sheared, regional mean circulation provides the needed energy for the enhanced eddy variability northeast of the Hawaiian archipelago.

[38] The EKE interannual variations northeast of the Hawaiian archipelago are well correlated to the PDO index with lags of 10-14 months. The underlying mechanism was speculated as follows: during the positive phase of the PDO index, positive anomalous Ekman pumping associated with a stronger Aleutian Low lifts the thermocline and lowers the $\mathrm{SSH}$. Since our study region is located south to the center of the Aleutian low, the anomalous SSH gradient is southeastward corresponding with the northeastward geostrophic flow. The anomalous northeastward flow is trapped in the upper layer so that it strengthens the eastward vertical shear of mean flow between the upper layer and the thermocline. The mean flow then becomes more baroclinic unstable and consequently produces higher EKE levels. The scenario for the negative phase of the PDO index is opposite, featuring weak baroclinic instability and lower EKE levels.
[39] Acknowledgments. The merged T/P and ERS-1/2 altimeter data (AVISO SSH anomalies) are provided by the CLS Space Oceanography Division as part of the Environment and Climate EU ENACT project and with support from CNES (ftp://ftp.cls.fr/). This study benefited from fruitful discussions with Ted Durland, Paulo Calil, and Reka Domokos. Comments made by the editor Frank Bryan and the anonymous reviewers helped improve the manuscript significantly. Support from NASA through contracts 1207881 and 1228847 is gratefully acknowledged.

\section{References}

Antonov, J. I., R. A. Locarnini, T. P. Boyer, A. V. Mishonov, and H. E. Garcia (2006), World Ocean Atlas 2005, vol. 2, Salinity, NOAA Atlas NESDIS 62, edited by S. Levitus, 182 pp., NOAA, Silver Spring, Md.

Calil, P. H. R., K. J. Richardsa, Yanli Jia, and R. R. Bidigare (2008), Eddy activity in the lee of the Hawaiian Islands, Deep Sea Res., Part II, 55, 1179-1194

Chen, S., and B. Qiu (2006), Annual variations in sea surface height northeast of the Hawaiian Islands, Geophys. Res. Lett., 33, L17612, doi:10.1029/2006GL027005.

Cheney, R. E., P. L. Richardson, and K. Nagasaka (1983), Global mesoscale variability from collinear tracks of Seasat altimeter data, J. Geophys. Res., $88,641-654$.

Chhak, K. C., E. Di Lorenzo, N. Schneider, and P. F. Cummins (2009), Forcing of low-frequency ocean variability in the northeast pacific, J. Clim., 22, 1255-1276.

Chiswell, S. M. (1996), Intra-annual oscillations at station ALOHA, north of Oahu, Hawaii, Deep Sea Res., Part II, 43, 305-319.

Cummins, P. F., G. S. E. Lagerloef, and G. Mitchum (2005), A regional index of northeast Pacific variability based on satellite altimeter data, Geophys. Res. Lett., 32, L17607, doi:10.1029/2005GL023642.

Halliwell, G. R., Jr., G. Peng, and D. B. Olson (1994), Stability of the Sargasso Sea Subtropical Frontal Zone, J. Phys. Oceanogr., 24, 11661183 .

Kobashi, F., and H. Kawamura (2001), Variation of sea surface height at periods of $65-220$ days in the subtropical gyre of the North Pacific, J. Geophys. Res., 106, 26,817-26,831.

Kobashi, F., and H. Kawamura (2002), Seasonal variation and instability nature of the North Pacific Subtropical Countercurrent and the Hawaiian Lee Countercurrent, J. Geophys. Res., 107(C11), 3185, doi:10.1029/ 2001JC001225.

Lee, D. K., and P. P. Niiler (1987), The local baroclinic instability of geostrophic spirals in the Eastern North Pacific, J. Phys. Oceanogr. 17, 1366-1377

Le Traton, P. Y., and G. Dibarboure (1999), Mesoscale mapping capabilities of multiple-satellite altimeter missions, J. Atmos. Ocean. Technol., 16 , $1208-1223$

Locarnini, R. A., A. V. Mishonov, J. I. Antonov, T. P. Boyer, and H. E. Garcia (2006), World Ocean Atlas 2005, vol. 1, Temperature, NOAA Atlas NESDIS 61, edited by S. Levitus, 182 pp., NOAA, Silver Spring, $\mathrm{Md}$.

Lumpkin, C. F. (1998), Eddies and currents of the Hawaiian Islands, Ph.D. dissertation, 281 pp., Univ. of Hawaii at Manoa, Honolulu.

Mantua, N. J., S. R. Hare, Y. Zhang, J. M. Wallace, and R. C. Francis (1997), A Pacific interdecadal climate oscillation with impacts on salmon production, Bull. Am. Meteorol. Soc., 78, 1069-1079.

Meredith, M. P., and A. M. Hogg (2006), Circumpolar response of Southern Ocean eddy activity to a change in the Southern Annular Mode, Geophys. Res. Lett., 33, L16608, doi:10.1029/2006GL026499.

Mitchum, G. T. (1995), The source of 90 day oscillations at Wake Island, J. Geophys. Res., 100, 2459-2475.

Mitchum, G. T. (1996), On using satellite altimetric heights to provide a spatial context for the Hawaii Ocean Time-series measurements, Deep Sea Res., Part II, 43, 257-280.

Niiler, P. (2001), The world ocean surface circulation, in Circulation and Climate Observing and Modeling the Global Ocean, edited by J. Church, G. Siedler, and J. Gould, pp. 193-204, Academic, San Diego, Calif.

Niiler, P., and R. W. Reynolds (1984), The three-dimensional circulation near the eastern North Pacific Subtropical Front, J. Phys. Oceanogr., 14, $217-230$.

Pedlosky, J. (1998), Ocean Circulation Theory, 453 pp., Springer, Berlin. Penduff, T., B. Barnier, W. K. Dewar, and J. J. O’Brien (2004), Dynamical response of the oceanic eddy field to the North Atlantic Oscillation: A model-data comparison, J. Phys. Oceanogr., 34, 2615-2629.

Qiu, B. (1999), Seasonal eddy field modulation of the North Pacific Subtropical Countercurrent: TOPEX/POSEIDON observations and theory, J. Phys. Oceanogr., 29, 2471-2486.

Qiu, B., and S. Chen (2005), Variability of the Kuroshio Extension jet, recirculation gyre and mesoscale eddies on decadal timescales, J. Phys. Oceanogr., 35, 2090-2103. 
Qiu, B., and S. Chen (2010), Interannual variability of the North Pacific Subtropical Countercurrent and its associated mesoscale eddy field, J. Phys. Oceanogr., 40, 213-225.

Qiu, B., and T. Durland (2002), Interaction between an island and the ventilated thermocline: Implications for the Hawaiian Lee Countercurrent, J. Phys. Oceanogr., 32, 3408-3426.

Qiu, B., D. Koh, C. Lumpkin, and P. Flament (1997), Existence and formation mechanism of the North Hawaiian Ridge Current, J. Phys. Oceanogr., 27, 431-444.

Roden, G. I. (1980), On the Subtropical Frontal Zone north of Hawaii during winter, J. Phys. Oceanogr., 10, 342-362.

Roden, G. I. (1981), Mesoscale thermohaline, sound velocity and baroclinic flow structure of the Pacific Subtropical Front during the winter of 1980, J. Phys. Oceanogr., 11, 658-675.
Van Woert, M. L., and J. M. Price (1993), Geosat and advanced very high resolution radiometer observations of oceanic planetary waves adjacent to the Hawaiian Islands, J. Geophys. Res., 98, 14,619-14,631.

Wyrtki, K. (1975), Fluctuations of the dynamic topography in the Pacific Ocean, J. Phys. Oceanogr., 5, 450-459.

Wyrtki, K., L. Magaard, and J. Hager (1976), Eddy energy in the oceans, J. Geophys. Res., 81, 2641-2646.

S. Chen and B. Qiu, Department of Oceanography, University of Hawai'i at Mānoa, 1000 Pope Rd., Honolulu, HI 96822, USA. (schen@soest. hawaii.edu) 